\title{
Role of Laparoscopic Surgery in the Management of Female Infertility at the Department of Gynecology of Hôpital du Mali
}

\section{Mamadou Bakary Coulibaly ${ }^{1}$, Alassane Traoré1, Mody Abdoulaye Camara ${ }^{2}$, Bourama Kané3, Adama Sangaré1, Kalba Tembiné4, Ibrahima Tégueté5, Youssouf Traoré5}

\author{
${ }^{1}$ Service of Gynecology of Hôpital du Mali, Bamako, Mali \\ ${ }^{2}$ Service of Medical Imaging of Hôpital du Mali, Bamako, Mali \\ ${ }^{3}$ Service of Pediatric of Hôpital du Mali, Bamako, Mali \\ ${ }^{4}$ Service of Anesthesia and Resuscitation of Hôpital du Mali, Bamako, Mali \\ ${ }^{5}$ Service of Gynecology-Obstetrics CHU Gabriel TOURE, Bamako, Mali \\ Email: *mbccolby1@yahoo.com
}

\begin{abstract}
How to cite this paper: Coulibaly, M.B., Traoré, A., Camara, M.A., Kané, B., Sangaré, A., Tembiné, K., Tégueté, I. and Traoré, Y. (2020) Role of Laparoscopic Surgery in the Management of Female Infertility at the Department of Gynecology of Hôpital du Mali. Open Journal of Obstetrics and Gynecology, 10, 1430-1440. https://doi.org/10.4236/ojog.2020.10100131
\end{abstract}

Received: September 1, 2020

Accepted: October 23, 2020

Published: October 26, 2020

Copyright $\odot 2020$ by author(s) and Scientific Research Publishing Inc. This work is licensed under the Creative Commons Attribution International License (CC BY 4.0).

http://creativecommons.org/licenses/by/4.0/

\begin{abstract}
Infertility is a socio-cultural drama in Africa, especially in Mali and remains difficult for couples to overcome. Laparoscopy, also called minimally invasive surgery or keyhole surgery, is an operative technique that permits to explore the pelvis and perform an appropriate therapeutic procedure. The objective of our work was to assess the role of laparoscopic surgery in the treatment of female infertility at Hôpital du Mali. It was a retrospective descriptive study that was conducted over a period of 5 years (January 2013 to December 2018). Any patients followed for infertility and who underwent laparoscopic surgery in the gynecology department over a period of two (2) years were included. The outcome of laparoscopic surgery was evaluated in terms of conception of pregnancy. We had collected 103 infertile patients out of 2984, with a frequency of $3.45 \%$. The mean age of our patients was 30.2 years. Housewives and out-of-school women accounted for $68.93 \%$ and $54.37 \%$ respectively. Nulligravida represented $41.75 \%$. Regarding infertility, it was primary in $41.75 \%$ and secondary in $58.25 \%$, with an average duration of 6.2 years. Systematic chlamydial serology was positive in $62.14 \%$ of our patients. Hysterosalpingography (HSG) revealed bilateral tubal obstruction in 53.33\% of cases. Laparoscopy found tubal adhesions in $97.80 \%$ of cases. Adhesiolysis was the main procedure performed with $84.47 \%$ bilateral tubal patency achieved in the methylene blue test. Among our patients who had contracted a pregnancy $(22.99 \%), 85 \%$ had carried their pregnancies to term. Tubal damage was the main cause of infertility. Adhesiolysis remains the main laparoscopic procedure for treatment.
\end{abstract}




\section{Keywords}

Laparoscopic Surgery, Infertility, Hôpital du Mali

\section{Introduction}

Infertility is a global public health issue and affects $8 \%$ to $12 \%$ of couples [1]. In France, $15 \%$ to $20 \%$ of couples consult for fertility problems at some point in their life [1]. In Africa, infertility is a social drama and a difficult ordeal for couples to overcome. Its rate varies from $7 \%$ to $21 \%$ depending on the regions [2]. The first cause of marital disagreement or divorce is considered a fatality, a fate or a curse inflicted on the couple. For the woman, it would represent a divine punishment because most of the time, she is the first to be blamed [2].

Tubal causes are the main etiology of infertility in Africa [2]. According to a study of the World Health Organization (WHO), bilateral tubal occlusion is 3 times more common in Africa than in the rest of the world (49\% versus 11\%) [1] [2]. The management of infertility in Africa is complex, due to the lack of adequate means of prevention and difficult access to new techniques such as laparoscopy and medically assisted procreation (MAP) [1] [2]. These techniques are slow to become popular in Africa because of their cost [1] [2].

Laparoscopy, also called minimally invasive surgery (MIS) or keyhole surgery, is an operative technique that allows exploration of the pelvis and a suitable therapeutic procedure to be proposed [3].

Tubal involvement is found in $25 \%$ to $35 \%$ of infertile women and represents $25 \%$ of the indications for in vitro fertilization followed by embryo transfer according to the national register of in vitro fertilization (FIVNAT) which manages the statistics of the assisted medical procreation (AMP) in France [4].

However, laparoscopy is the gold standard for assessing tubal patency. Its objective is twofold: to diagnose and possibly, according to the management strategy, to correct anatomical anomalies [5]. Fimbrioplasty and neosalpingostomy respectively improve and restore the permeability of the distal portion of the tube: fimbrioplasty consists of reconstitution of the pinna as in its natural state from the old tubal ostium and neosalpingostomy allows creating a tubal ostium. Laparoscopy can considerably reduce the length of hospital stay, operative risks and post-operative complications compared to laparotomy [5].

Endoscopic surgery introduced in Mali in 2001, is in our work setting the main method used to treat distal tubal infertility. Although its results are often poor [6] [7], it permits a curative treatment of tubal occlusion and offers to the patient the possibility to expect babies without using assisted medical procreation that is hardly available in Mali.

A study carried out in Mali at the Point G University Hospital by S KEITA had obtained a pregnancy in $32.5 \%$ of cases after the laparoscopy [8].

The hospital of Mali, which is a 3rd referral structure, is equipped with a la- 
paroscopic surgery column. He started laparoscopy in 2012, just one year after opening. We initiated this study which aimed to study the role of laparoscopic surgery in the management of female infertility.

\section{Patients and Method}

This was a retrospective descriptive study that was conducted over a period of 5 years (January 2013 to December 2018). Any women with infertility who had visited the gynecology department of Hospital du Mali and who underwent laparoscopic surgery were included. Any woman who consulted for infertility and who did not undergo laparoscopic surgery was excluded.

We had studied several variables:

- sociodemographic aspects: age, marital status and level of education,

- the process of performing laparoscopic surgery,

- preoperative conditions: type and duration of infertility, gyneco-obstetric history, results (ultrasound and HSG) and infectious assessment,

- intraoperative variables: lesions observed, procedures performed (adhesiolysis, end-to-end tubal recovery, fimbryo-neostomy, drilling, myomectomy and cystectomy),

- post-operative variables (follow-up assessment, lost to follow-up, the interval between surgery and the occurrence of pregnancy, additional treatments),

- the result of laparoscopic surgery (becoming pregnant and progressing of pregnancies).

The patients were followed on at least two (02). Our data was collected on a survey sheet from the patient's records and the operative report registers. They were supplemented by telephone calls from patients and their families. The data is processed and analyzed by using Word, Excel software,

\section{Results}

We recruited 103 patients out of 2984 treated in the service for infertility, with a hospital frequency of $3.45 \%$. The average age of our patients was 30.2 years \pm 14.53 with extremes from 18 to 48 years. These were housewives (68.93\%), out of school (54.37\%). Among our patients, nulligravida accounted for $41.75 \%$ and primiparous $63.11 \%$. The history of manual intrauterine (MIU) aspiration and pelvic surgery concerned $78.43 \%$ and $37.24 \%$ of our patients, respectively. The pelvic exam was unremarkable. The average duration of infertility was 6.2 years, with extremes ranging from 2 to 14 years. Infertility was primary $(41.75 \%)$ and secondary (58.25\%) (Table 1). Chlamydia serology was positive in $62.14 \%$ of patients. Pelvic ultrasound returned to normal in $86.41 \%$ of cases. The main abnormalities found out on HSG were: bilateral tubal obstruction (53.33\%) (Figure 1 ), and bilateral hydrosalpinx (32.22\%) (Figure 2). The main lesions found on laparoscopic examination were: tubal adhesions (97.80\%), bilateral hydrosalpinx (34.06\%) and tubal phimosis (23.08\%) (Table 2). The main procedures performed were: adhesiolysis (69.23\%), neo-salpingostomy (23.08\%), fimbrioplasty 
and drilling or ovarian drilling (each 15.38\%) (Figure 3). Bilateral tubal patency was pointed out in $84.47 \%$ of patients tested with methylene blue (Figure 4 ). Patients who became pregnant was $22.99 \%$ of cases (Figure 5 ). The main laparoscopic procedures leading to these results were: adhesiolysis (55\%), ovarian drilling (40\%), cystectomy (5\%) (Table 3). The time to pregnancy conception was 1 to 3 months in $55 \%$ of our patients. The pregnancies had progressed to term in $85 \%$ of cases. We had recorded $10 \%$ of spontaneous abortion cases, and $5 \%$ of ectopic pregnancies. The patients lost to follow-up were evaluated at $15.53 \%$. There had been no per- and post-operative complications.

Table 1. Maternal characteristics.

\begin{tabular}{|c|c|c|c|c|}
\hline \multicolumn{3}{|c|}{ Maternal characteristics } & \multirow[t]{2}{*}{ Number } & \multirow[t]{2}{*}{ Percentag } \\
\hline Mean age & 30.2 years & & & \\
\hline \multicolumn{5}{|c|}{ Educational level } \\
\hline No sc & hooling & & 56 & 54.37 \\
\hline Prima & ry level & & 12 & 11.65 \\
\hline Second & ary level & & 9 & 8.73 \\
\hline High & er level & & 26 & 25.25 \\
\hline \multicolumn{5}{|c|}{ Gravida } \\
\hline Nulli & gravida & & 43 & 41.75 \\
\hline Primi & gravida & & 30 & 29.12 \\
\hline Pauci & gravida & & 23 & 22.33 \\
\hline Multi & gravida & & 7 & 6.80 \\
\hline \multicolumn{5}{|c|}{ Parity } \\
\hline Nulli & parous & & 65 & 63.11 \\
\hline Primi & parous & & 28 & 27.18 \\
\hline Pauci & parous & & 10 & 9.71 \\
\hline Average duration of infer & ility (in years) & 6.2 years & & \\
\hline & -5 & & 34 & 33 \\
\hline & -8 & & 44 & 42.72 \\
\hline 9 an & over & & 25 & 24.28 \\
\hline
\end{tabular}


Table 2. Distribution according to the type of lesion observed on laparoscopy.

\begin{tabular}{ccc}
\hline Type of lesions & Number & Percentage \\
\hline Tubal adhesion & 89 & 97.80 \\
Unilateral hydrosalpinx & 17 & 18.68 \\
Bilateral hydrosalpinx & 31 & 34.06 \\
Bilateral ovarian cyst & 0 & 0 \\
Unilateral ovarian cyst & 8 & 8.79 \\
Myomas & 01 & 1.10 \\
Tubal phimosis & 21 & 23.08 \\
Tubal endometriosis & 01 & 1.10 \\
None & 12 & 11.65 \\
\hline
\end{tabular}

Table 3. Distribution according to occurrence of pregnancy depending on surgical procedure performed.

\begin{tabular}{ccc}
\hline \multirow{2}{*}{ Surgical procedure performed } & \multicolumn{2}{c}{ Occurrence of pregnancy } \\
\cline { 2 - 3 } & Number & Percentage \\
\hline Adhesiolysis & 11 & $55 \%$ \\
Cystectomy & 1 & $5 \%$ \\
Drilling (ovarian drilling) & 8 & $40 \%$ \\
Total & 20 & $100 \%$ \\
\hline
\end{tabular}

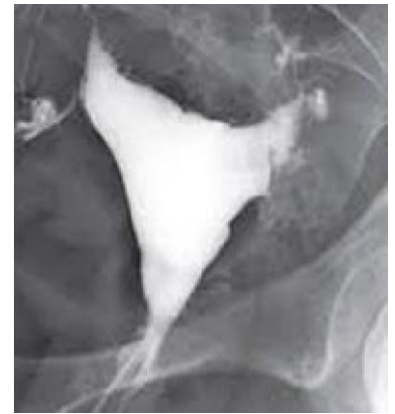

Figure 1. HSG from a 32-year-old patient showing bilateral tubal obstruction: left proximal, and right distal.
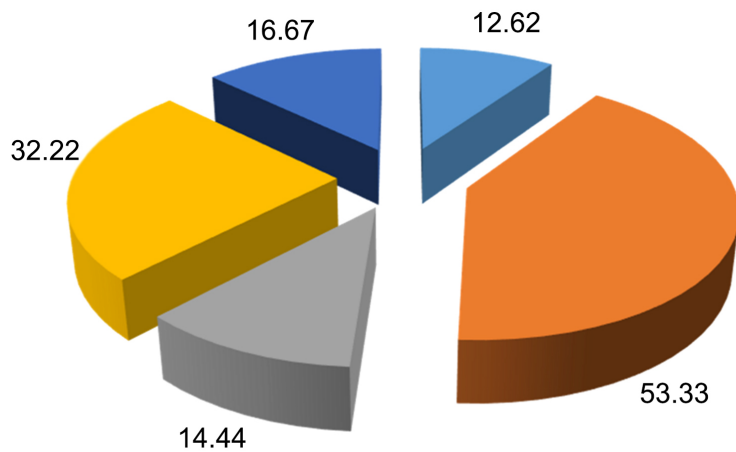

$\square$ Normal

$\square$ Bilateral tubal obstruction

$\square$ Unilateral tubal obstruction

$\square$ Bilateral hydrosalpinx

- Unilateral hydrosalpinx

Figure 2. Distribution according to the result of the hysterosalpingography. 


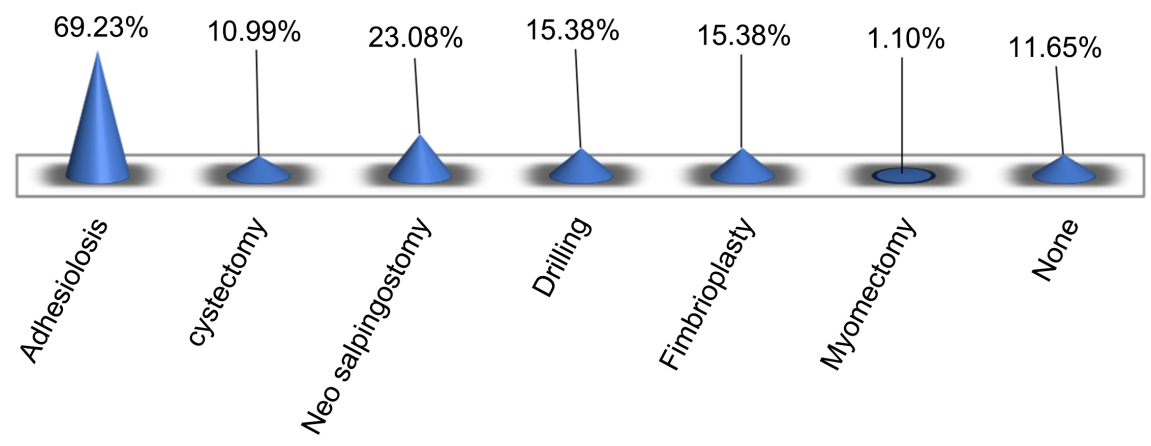

Figure 3. Distribution according to the surgical procedure performed.

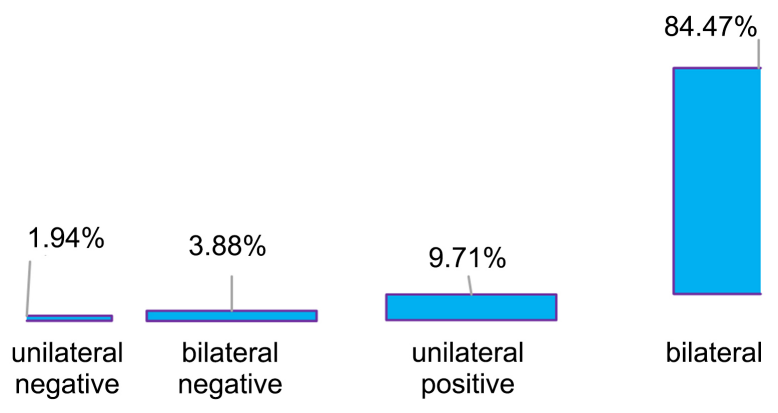

Figure 4. Distribution according to occurrence of pregnancy.

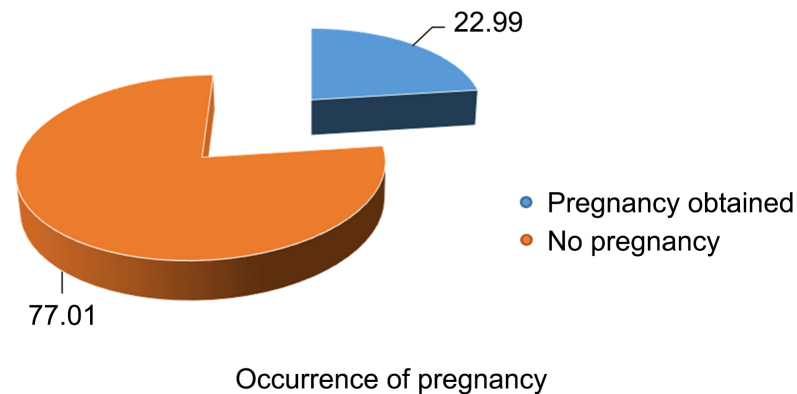

Figure 5. Distribution according to the methylene blue test.

\section{Discussion}

Age: The mean age of our patients was 30.2 years \pm 14.53 . Our data could be compared to those of Kaouther Dimassi et al. [9] (34 years) and Khaled Boudhraa et al. [10] in Tunisia (33, 3 years). Floriane Silvente-Fernandez et al. [11] in France reported an average age of 31 years.

The level of education: Our patients were not educated in $54.37 \%$ of cases. This was comparable to the $52 \%$ of Kaouther Dimassi et al. [9] and $55.5 \%$ of Mahamadou Diabaté et al. [12].

Gravidity and parity: We found out $41.75 \%$ of nulliparous. This rate was close to that of Salma Ait Batahar who reported 40.5\% [13]. However, it was lower than that of Kaouther Dimassi 33\% [4] and of Floriane Silvente-Fernandez $30.5 \%$ [11]. In our study, we found out $63.11 \%$ of primipara. This rate was higher than that of Kaouther Dimassi et al. (50.5\%) [9] and Yaële Dadoun (48.65\%) 
[14]. These could be accounted for by the total pregnancy rate which is higher in our context (7.2 children per woman).

A history of MIU aspiration was figured out in $78.43 \%$ of our patients. Our data were lower than those of other authors such as Salma Ait Batahar (26.93\%) [8], Khaled Boudhraa (12\%) [10], or Yaële Dadoun (11.1\%) [14]. The history of pelvic surgery was about $37.24 \%$ of our patients. These data were parallel to those of Khaled Boudhraa [10] and Salma Ait Batahar [13] who reported 35.5\% and $34.65 \%$ respectively. They were lower than those of Yaël Dadoun [14] (40.6\%), Floriane Silvente-Fernandez [11] (43\%) and Kaouther Dimassi [9] (50\%).

Infectious origin: Chlamydia serology was positive in $62.14 \%$ of our patients. Our data were comparable to that of DK Tran (65\%) [15], but higher than those of Salma Ait Batahar, (25\%) [13], Yaële Dadoun (27\%) [14] and Kaouther Dimassi (5.76\%) [9] Chlamydiae trachomatis is the pathogen most implicated in infectious tubal damage [4] [16].

The nature of infertility: It was primary in $41.75 \%$ of our patients, and secondary in $58.25 \%$. Our data were parallel with those of Khaled Boudhraa [10] who reported $46 \%$ primary infertility and $54 \%$ secondary infertility. However, they were different from those of other authors such as Salma AIT BATAHAR [8] who reported (56.25\%) and (43.75) respectively for primary and secondary infertility. In the series by Floriane Silvente-Fernandez [11], primary infertility concerned $56 \%$ of patients and secondary infertility $44 \%$. Kaouther Dimassi [9] pointed out $32.7 \%$ for primary infertility and $67.30 \%$ for secondary infertility.

Duration of infertility: The average duration of infertility in our series was 6.2 years, with extremes from 2 years to 14 years. These data were superimposable on those of authors like Khaled Boudhraa et al. [10] who have reported an average duration of 5.42 years with extremes from 3 to 13 years. It was also 7.43 years in the series of Salma Ait Batahar [13], with extremes ranging from 2 years to 20 years. Our data were different from those of authors like Kaouther Dimassi [9] who found out an average duration of infertility of 4 years with extremes ranging from 1 year to 16 years. Floriane Silvente-Fernandez [11], in her series had figured out an average duration of 3 years, with extremes from 2 years to 12 years.

Pelvic ultrasound: All of our patients had undergone at least one pelvic exploration on ultrasound and this was normal in $86.41 \%$ of cases. This pelvic ultrasound normal rate was higher than that of Kaouther Dimassi [9] and Khaled Boudhraa [10] who reported $60 \%$ and $59 \%$ respectively.

Hysterosalpingography (HSG): Particularly indicated in infertility, because it specifies the condition of the uterine cavity and tubal patency. It is essential in the exploration of the tubes, as it allows the dynamic tubal study and the localization of the tubal obstacle. All our patients had benefited from this HSG. The main abnormalities found out were: bilateral tubal obstruction (53.33\%), bilateral hydrosalpinx (32.22\%), unilateral hydrosalpinx (16.67\%). Our data differed 
from those of Kaouther Dimassi [9], who figured out 13.46\% bilateral tubal obstruction, $61.53 \%$ bilateral hydrosalpinx, and $15.38 \%$ bilateral tubal phimosis. Salma Ait Batahar [13] reported $70.83 \%$ of tubal patency, $45.83 \%$ of hydrosalpinx, $10.41 \%$ of tubal ectasia.

Laparoscopic exploration: The main lesions found out on laparoscopic exploration in our series were: tubal adhesions (97.80\%), bilateral hydrosalpinx (34.06\%), tubal phimosis (23.08\%). They were tubo-ovarian adhesions in $40.05 \%$; tubo-pelvic in $27.08 \%$ omentum uterine in $16.05 \%$, tubo-peritoneal $10.01 \%$ and very rigid utero-pelvic in $4.61 \%$. Our data were close to those found out by the following authors: Salma Ait Batahar [13] who observed that adhesions were the most common lesions (with 47.91\%), followed by hydrosalpinx (45.8\%), tubal phimosis (18.75\%). In Salma Ait Batahar's series [13], the adhesions were: tuboperitoneal in $45.8 \%$, tubo-pelvic in $22.9 \%$, tubo-ovarian in $25 \%$ of cases, and one case of hepatic adhesions in the context of the Fitz-Hugh and Curtis syndrome. Floriane Silvente Fernandez [11] reported that the main lesions pointed out were also pelvic adhesions (53\%), hydrosalpinx (36\%), tubal phimosis (22\%). In her series, the adhesions were tubo-peritoneal (57\%), tubo-pelvic in (34\%), tubo-ovarian in $(18 \%)$ of cases, and hepatic adhesions (5\%) in the context of Fitz-Hugh and Curtis syndrome. Kaouther Dimassi [9], figured out $88 \%$ of pelvic adhesions associated or not with Fitz Hugh Curtis syndrome, bilateral hydrosalpinx (26.92\%), tubal phimosis (1.92\%). Khaled Boudhraa's [10] data were different from those of the authors where pelvic adhesions and endometriosis were the main lesions in $27.14 \%$ and $17.14 \%$ respectively. These adhesions were mainly peri-ovarian and peri-tubal, bilateral in $52.6 \%$ of cases and thick and very dense in $55.26 \%$ of cases. Endometriosis cases were associated with $71 \%$ of the causes of primary infertility in his series.

The nature of the operative processing: The operative procedures can be simple or combined. In our series, the main procedures performed were: adhesiolysis (69.23\%), neo-salpingostomy (23.08\%), fimbrioplasty and ovarian drilling (15.38) each. Our data were parallel to those of the authors such as: Ngaroua [17] who came across with (81.60\%) of adhesiolysis, fimbrioplasty (39.60\%), neostomy (34.10\%). The data from Salma Ait Batahar [13] were as follows: adhesiolysis (70.8\%), fimbrioplasty (47\%) neostomy (20.5\%). Khaled Boudhraa [10] had performed (27.1\%) adhesiolysis, laparoscopic surgery for infertility. Our operative procedures as well as those of Ngaroua [17], Salma Ait Batahar [13], Khaled Boudhraa [12] were different from those of the authors like Kaouther Dimassi [9], who indicated that the main procedures were neosalpingostomy (51.92\%), fimbrioplasty (28.84\%) and adhesiolysis (26.92\%). Floriane Silvente-Fernandez [11], reported $22 \%$ of fimbrioplasty, $21 \%$ of neosalpingostomy, $18 \%$ of salpingectomy, and only $9 \%$ of adhesiolysis.

Post-operative tubal patency, especially after neosalpingostomy, was a reflection of the purely technical aspect and also the achievement of one of the objectives of the intervention. In our series, this patency was pointed out in $84.47 \%$ of 
patients tested with methylene blue. This rate was higher than those of authors such as: Kaouther Dimassi [9] (67\%), Ngaroua [17] (42.6\%). It was lower than that of Floriane Silvente-Fernandez, 93\% [11] and Yaële Dadoun, 89\% [14].

The occurrence of pregnancy: In our series, the rate of patients who became pregnant was $22.99 \%$, including: $55 \%$ after adhesiolysis, $40 \%$ after ovarian drilling, 5\% after cystectomy. The time to conception was 1 to 3 months in $55 \%$ of our patients. The great majority of pregnancies (85\%) progressed to term, $10 \%$ were spontaneously aborted, and ectopic pregnancy in $5 \%$ of cases. The rate of becoming pregnant in the series of Kaouther Dimassi [9] was $8.69 \%$, or $13 \%$ after fimbrioplasty and $4 \%$ after neosalpingostomy. Ngaroua [17] reported 20.5\% of conceived pregnancies, $64.1 \%$ of which progressed to term, $15.4 \%$ resulting in spontaneous abortions. Yaële Dadoun [13] reported 62\% of conceived pregnancies, of which $56.2 \%$ intrauterine and $5.6 \%$ of pregnancy. Among the pregnancies, $42 \%$ were spontaneous, $4 \%$ occurred after intrauterine insemination and $54 \%$ after in-vitro fertilization (IVF). Intrauterine pregnancies in his series were spontaneously conceived after neosalpingostomy and fimbrioplasty in $27 \%$ and $50 \%$, respectively. In the series of Salma Ait Batahar [13], the pregnancy conception rate was $43.4 \%$, of which $39.13 \%$ was intrauterine pregnancy and $4.3 \%$ ectopic pregnancy. Almost $30.4 \%$ of pregnancies were conceived after tubal plastic surgery. Floriane Silvente-Fernandez [11] reported 43 pregnancies, 37\% were spontaneous and $63 \%$ obtained after medically assisted procreation

We had lost to follow-up $15.53 \%$ of our patients. This rate was $46 \%$ in the series by Floriane Silvente-Fernandez [11], 10\% in Yaële Dadoun [9], 14.58\% in Salma Ait Batahar [13]. We had no intra or postoperative complications. The same observation was made by the authors [9] [11] [13] [14].

The limitations and difficulties encountered during the study were mainly linked:

- The retrospective nature of the collection, of certain missing or incomplete information noted on the collection media.

- Patients lost to follow-up (16 in number) due to non-existent or non-functional telephone contacts.

- The lack of a medically assisted reproduction (IVF) unit.

- Lack of information on the benefit of laparoscopy.

It appears that after our study, laparoscopy is a good means of treatment of female sterility.

We had obtained $22.9 \%$ pregnancy and a short duration of hospitalization after the surgery.

\section{Conclusion}

Tubal lesion is still the main cause of female infertility. Laparoscopic surgery alone or in addition to medically assisted procreation techniques remains the medical alternatives for conceiving pregnancies. However, a rigorous selection of patients who are eligible for this type of treatment remains necessary. 


\section{Conflicts of Interest}

The authors declare no conflicts of interest regarding the publication of this paper.

\section{References}

[1] Boivin, J., Bunting, L., Collins, J.A. and Nygren, K.G. (2007) International Estimates of Infertility Prevalence and Treatment-Seeking: Potential Need and Demand for Infertility Medical Care. Human Reproduction, 22, 1506-1512. https://doi.org/10.1093/humrep/dem046

[2] Meheus, A., Reniers, J. and Colletet, M. (1986) Determinants of Infertility in Africa. Afr J Sex Transmi Dis, 2, 31-35.

[3] Yazbeck, C., Fauconnier, A. and Pouly, J.L. (2010) Reproductive Surgery. Journal de Gynécologie Obstétrique et Biologie de la Reproduction, 39, 75-87. https://doi.org/10.1016/S0368-2315(10)70033-8

[4] Practice Committee of the American Society for Reproductive Medicine (2015) Role of Tubal Surgery in the Era of Assisted Reproductive Technology: A Committee Opinion. Fertility and Sterility, 103, e37-e43. https://doi.org/10.1016/j.fertnstert.2015.03.032

[5] Torre, A., Pouly, J.-L. and Wainer, B. (2010) The Anatomical Assessment of the Woman of the Infertile Couple. Journal de Gynécologie Obstétrique et Biologie de la Reproduction, 39, S34-S44. https://doi.org/10.1016/S0368-2315(10)70029-6

[6] Jeffrey, B.R., Alan, H.D., Neri, L., Mary, L.P., Frederick, N. and Phil, D. (1986) Neosalpingostomy: Comparison of 24- and 72-Month Follow-Up Time Shows Increased Pregnancy Rate. Fertility and Sterility, 45, 296-298. https://doi.org/10.1016/S0015-0282(16)49171-5

[7] Alan, G. (1971) Infertility Surgery of the Oviduct. Fertility and Sterility, 22, 496-503. https://doi.org/10.1016/S0015-0282(16)38403-5

[8] Soumaila, K., Youssouf, T. and Lamine, S. (2019) Fertility after Neosalpingostomy through Laparoscopic Way in Point "G" Teaching Hospital. Surgical Science, 10, 49-58. https://doi.org/10.4236/ss.2019.102007

[9] Dimassi, K., Gharsa, A., Chanoufi, M.B., Sfar, E. and Chelli, D. (2014) Results of Tubal Plastic Surgery: A Tunisian Study. Pan African Medical Journal, 18, 58. https://doi.org/10.11604/pamj.2014.18.58.4128

[10] Boudhraa, K., Jellouli, M.A., Kassaoui, O., Aissia, N.B., Ouerhani, R., Triki, A. and Gara, M.F. (2009) Role of Hysteroscopy and Laparoscopy in the Management of Infertile Couples in 200 Cases. Tunisian Medical, 87, 55-60.

[11] Silvente-Fernandez, F., et al. (2018) Surgical Management of Tubo-Peritoneal Infertility at the CAEN CHU between 2005 and 2014. Thesis Med., Faculty of Medicine, University of Caen Normandie, Caen.

[12] Diabaté, M., et al. (2011) Infertility of the Couple: Psychosocial Aspects in Women at the Mother-Child Hospital: <Luxembourg>. Thesis Med., Faculty of Medicine, Pharmacy and Odontostomatology of Bamako, Bamako.

[13] Batahar, S.A. (2008) Place of Laparoscopy in the Treatment of Tuboperitoneal Infertility. Med. Thesis, No. 37, Faculty of Medicine and Pharmacy Marrakech, Cadi Ayyad University, Marrakesh.

[14] Dadoun, Y. (2016) Tubal Surgery for Female Infertility: About 207 Patients Operated on at the Regional and University Hospital of Lille between 2009 and 2014. 
Med. Thesis, Faculty of Medicine Henri Warembourg, University Lille 2 Law and Health.

[15] Tran, D.K. and Leroy, J.L. (1996) Tubo-Peritoneal Sterility. In: Encycl. Méd. Chir., Elsevier, Paris, Gynecologie, 750-A-10, 14 p.

[16] Wilson, J.S., Honey, E., Templeton, A., Paavonen, J., Mårdh, P.-A., Stary, A., et al. (2002) A Systematic Review of the Prevalence of Chlamydia trachomatis among European Women. Human Reproduction Update, 8, 385-394. https://doi.org/10.1093/humupd/8.4.385

[17] Ngaroua, C.F., Dieudonné, D. and Joseph, E.N. (2019) Contribution of Laparoscopic Surgery in the Healthcare Management of Female Infertility in Cameroon. 